\title{
Influence of pain in strength, resistance and recruitment of trunk muscles
}

\author{
Influência da dor na força, resistência e recrutamento dos músculos do tronco
}

\author{
Guilherme Thomaz de Aquino Nava', Beatriz Mendes Tozim², Mary Hellen Morcelli², Marcelo Tavella Navega²
}

DOI 10.5935/2595-0118.20180059

\section{ABSTRACT}

BACKGROUND AND OBJECTIVES: Changes in motor control may contribute to muscle recruitment deficits. The objective of this study was to evaluate strength, endurance, and recruitment of the torso muscles.

METHODS: We evaluated 35 women, divided into two groups: chronic low back pain (LBPG, $\mathrm{n}=20$ ) and control (CG, $\mathrm{n}=15$ ). The clinical conditions, incapacity, level of pain, strength, endurance and the muscles recruitment: internal oblique (IO) and external oblique (EO), rectus abdominis (RA), lumbar iliocostal (LI) and lumbar multifidus (LM) were evaluated. MANOVA, MANCOVA and Kruskal-Wallis were used.

RESULTS: There was no significant difference between groups in the muscle strength test $(\mathrm{p}<0.172)$. The control group showed the greater capacity for muscle endurance in the muscle endurance test $(\mathrm{p}<0.001)$. In muscle recruitment, the chronic low back pain group presented greater muscle activation, which was evident in the global stabilizing muscles EO and RA ( $\mathrm{p}<0.05)$.

CONCLUSION: Women with back pain had reduced muscular endurance and greater recruitment of the global muscles when compared to women with no back pain.

Keywords: Electromyography, Lumbar pain, Muscle strength, Physical resistance.

\section{RESUMO}

JUSTIFICATIVA E OBJETIVOS: Alteraçôes no controle motor podem contribuir para déficits no recrutamento muscular. $\mathrm{O}$ objetivo deste estudo foi avaliar a força, resistência e o recrutamento dos músculos do tronco.

MÉTODOS: Foram avaliadas 35 mulheres, divididas em dois grupos: dor lombar crônica (GDL, $\mathrm{n}=20$ ) e controle (GC, $\mathrm{n}=15)$. Avaliou-se as condiçóes clínicas, incapacidade, nível da

1. Universidade Estadual Paulista, Instituto de Biociências, Departamento de Educaçăo Física, Rio Claro, SP, Brasil.

2. Universidade Estadual Paulista, Faculdade de Filosofia e Ciências, Departamento de Fisioterapia e Terapia Ocupacional, Marília, SP, Brasil.

Submitted on March 11, 2018.

Accepted for publication on August 20, 2018.

Conflict of interests: none - Sponsoring sources: none.

Correspondence to:

Av. Hygino Muzzi Filho, 737 - Mirante

17525-000 Marília, SP, Brasil.

E-mail: gtanava@gmail.com

(C) Sociedade Brasileira para o Estudo da Dor dor, força, resistência e recrutamento dos músculos: oblíquo externo (OE) e interno (OI), reto abdominal (RA), iliocostal lombar (ICL) e multífido lombar (MUL). Utilizou-se MANOVA, MANCOVA e Kruskal-Wallis.

RESULTADOS: No teste de força muscular não houve diferença significativa entre os grupos $(\mathrm{p}=0,172)$. O grupo controle demonstrou maior capacidade de resistência no teste de resistência muscular $(\mathrm{p}<0,001)$. No recrutamento muscular, o grupo dor lombar crônica apresentou ativaçáo muscular maior, que ficou evidente nos músculos estabilizadores globais, OE e RA $(p<0,05)$.

CONCLUSÁO: Mulheres com dor lombar apresentaram resistência muscular diminuída e maior recrutamento nos músculos globais, quando comparadas às mulheres sem dor lombar.

Descritores: Dor lombar, Eletromiografia, Força muscular, Resistência física.

\section{INTRODUCTION}

Low back pain (LBP) is defined as pain or discomfort on the lumbar spine, lumbosacral or sacroiliac regions, being considered one of the main musculoskeletal dysfunctions of the current time $^{1-3}$. Approximately $80 \%$ of the population will have some LBP episode in its lifetime, and among these, approximately $62 \%$ will have a recurrence after one year $^{2-6}$. The etiology of chronic low back pain (CLBP) and its natural course are important issues not yet well understood, and approximately $90 \%$ of the CLBP cases do not have a defined or identifiable etiology, making treatment more difficult ${ }^{1,5}$. Studies were conducted to evaluate the relationship between the strength and endurance of the torso extensors and CLBP, which is a phenomenon related to long-term disability ${ }^{1.6}$.

One of the hypotheses for the changes in muscle strength and endurance are the alterations in the neural adaptation and consequent modification in the motor control ${ }^{7,8}$. This theory suggests that changes at different levels of the nervous system can result in the redistribution of muscle activity and change in the mechanical behavior, which can lead to deficits in the postural control of the torso muscles ${ }^{6,8,9}$. However, this relationship between strength, endurance, and muscle recruitment of the stabilizer torso muscles was poorly addressed. Therefore, it is evident how important it is to assess the recruitment of the torso muscles simultaneously to the assessment of the muscle strength and endurance parameters. Thus, to assess the muscular system, it is important to divide it into local and global muscles according to their functions $s^{8,10}$.

The literature describes surface electromyography as an instrument with characteristics that allow the evaluation of the torso muscles function of healthy and injured individuals $s^{5,11,12}$. 
The objective of this study was to evaluate the strength, endurance, and recruitment of the torso muscles in women with CLBP.

\section{METHODS}

Observational, cross-sectional study conducted with 35 women aged between 30 and 59 years, of which 20 were in the chronic low back pain group (LBPG, average age 46.6 \pm 8.34 years), based on personal report and pain location. The control group (CG) had 15 participants who did not have LBP (CG, average age $39.8 \pm 8$ years). The eligibility criteria for the LBPG were no practice of physical activity and having recurrent idiopathic CLBP for at least three months prior to the study. For the CG was no practice of any physical activity and no previous report of LBP. Non-eligibility criteria for both groups were: nerve compression on lower limbs (LL), pregnancy, history of severe cardiorespiratory problems, LL discrepancy, rheumatic, neurological or vestibular diseases, lumbar spine surgery, uncorrected visual alteration or being unable to understand the task. The exclusion criteria were: unable to perform any step of the data collection or any complication related to the collection procedure $(\mathrm{n}=2)$.

The sample calculation was obtained by the G*Power software, performed from a pilot study (data of five participants in each group). The time values of the muscle endurance test were used for the sample calculation. It was used the power of $0.95, \alpha$ error probability of 0.05 , the effect size of 1.614 , and it was estimated the need for 8 participants per group.

The data collection procedure consisted of clinical assessment, dorsal muscles strength test (MST) using a dorsal dynamometer, muscle endurance test (MET) by the Biering Sorensen test associated with surface electromyography of the torso stabilizer muscles. The Roland Morris Disability Questionnaire (RMDQ) was also used. The clinical evaluation consisted in collecting data on the dominance of LL used to place the electrodes in the electromyographic assessment, and data about the pain, such as its location, duration, intensity, the presence of paresthesias and use of pain relief drugs. The intensity was quantified by the visual analog scale (VAS). The VAS is a reliable and easy-to-apply method that quantifies the pain ${ }^{13}$. The scale has a horizontal line of $100 \mathrm{~mm}$. On the left end, there are the words "no pain/discomfort," and on the right, "worst pain/discomfort imaginable"13. To measure the pain, the participant was asked to inform the pain felt at the time of the evaluation and the intensity of the referred pain on a daily basis ${ }^{14}$. When finished, the measurement was performed with a ruler from the end "without pain/discomfort" to quantify the test ${ }^{13,15}$.

The RMDQ is an instrument that aims to determine the degree of disability due to the presence of LBP. It was translated and validated for the Portuguese language and consists of 24 self-respond questions ${ }^{16}$. The RMDQ is straightforward. The participants must check "yes" or "no" in the options that best represent their current state regarding the presence of LBP, varying from zero to 24 . Zero means no complaints, and as the result increases, the greater the incapacity to perform activities. The maximum result of 24 indicates participants with severe limitations ${ }^{16}$.
After the clinical evaluation, the MST of the torso extensors was performed using a dorsal dynamometer (Oswaldo Filizona), (Figure 1). For the MST, the participants were instructed to position their feet on a given location and exert a tensile force in the direction of the torso extension, and not to exert force with the upper limbs (UL) nor bend the $\mathrm{LL}^{17}$. The test was performed twice at the beginning, and twice at the end of the collection, for familiarization with the task ${ }^{18}$. The highest value of the second attempt was used for analysis ${ }^{18}$. At each attempt, the participants were stimulated verbally to keep the contraction for 4 seconds, with a 1 -minute rest ${ }^{1,11}$.

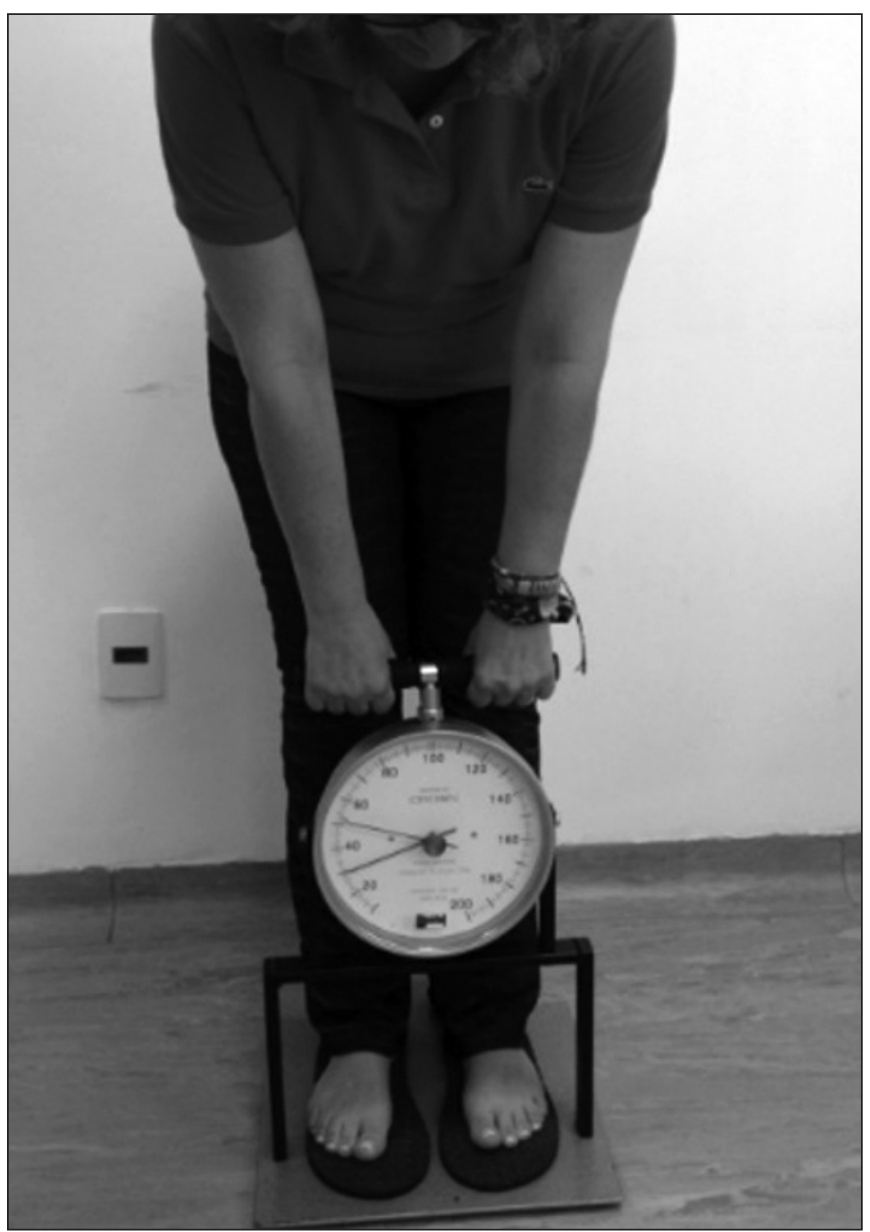

Figure 1. Muscle strength test

For the MET, participants were put in the prone position on a wooden box made for this purpose, which was placed on the stretcher. The anterior superior iliac spine (ASIS) was positioned on the anterior end of the box, and the participants were stabilized with Velcro straps on the region of the hip, knees, and ankles ${ }^{19}$. The torso was kept outside of the wooden surface and initially sustained on a foam. The participants were instructed to cross the UL anteriorly to the torso during the test, and this position was defined as neutral (Figure 2). After the positioning, the maximum time that the participants remained in the neutral torso position, without the aid of the hands, was clocked. The test had a maximum duration of 240 seconds, and it finished in the presence of fatigue or pain that precluded its continuity ${ }^{19}$. 


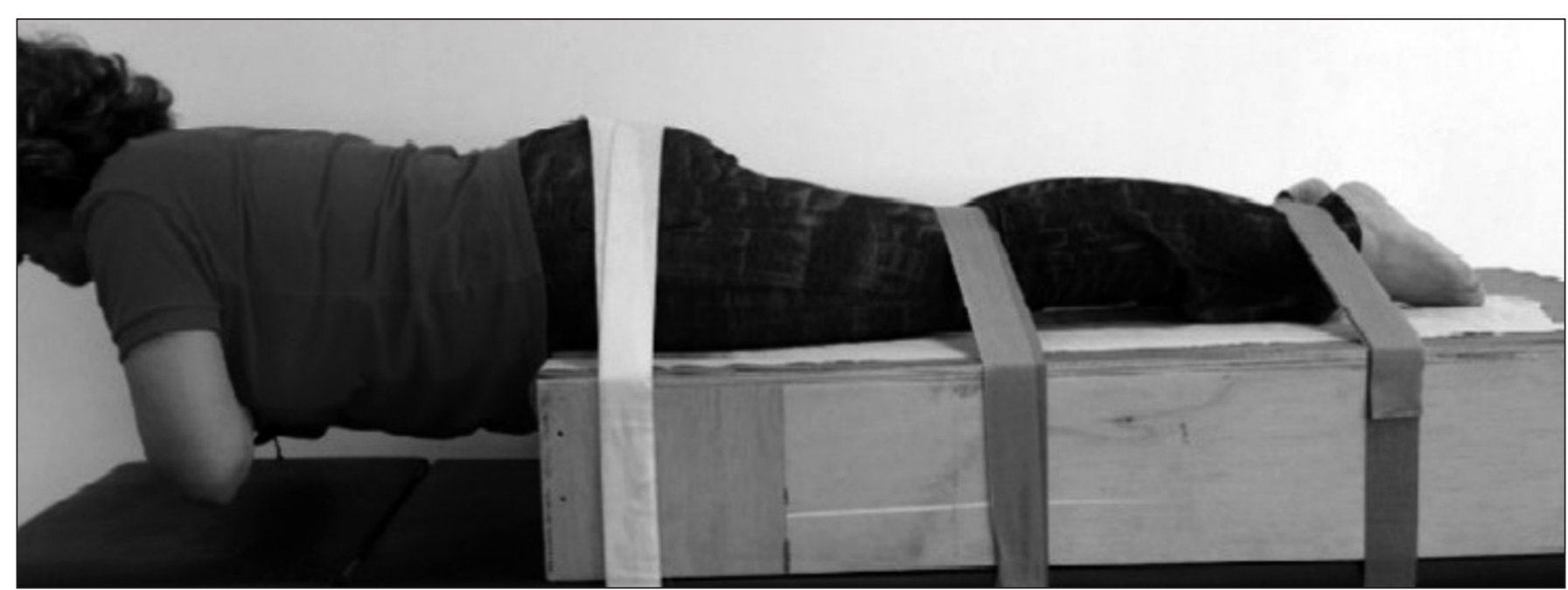

Figure 2. Muscle endurance test

Fatigue was considered as the moment when the participants could no longer maintain enough muscle contraction to keep the horizontal position of the body ${ }^{19}$. During the MET, electromyographic signals were collected from the local and global muscles on the dominant side of each participant. We used the dominance test that consisted of three tests, going up and down the stairs, kick a ball on target, and anterior displacement test ${ }^{20}$. For the electromyography, the selected local muscles were the internal oblique muscle (IO) and the lumbar multifidus (LM). And the selected global muscles were the external oblique (EO), the rectus abdominis (RA) and the iliocostalis lumborum (ICL). The participants were positioned in the supine position for the location and placement of the electrodes:

- RA: $1 / 2$ of the distance between the xiphoid process and the umbilical, approximately $3 \mathrm{~cm}$ lateral to the median line ${ }^{15}$.

- IO: $2 \mathrm{~cm}$ medially and below the ASIS ${ }^{21}$.

- EO: $50 \%$ of the distance between the lower rib cage and ASIS ${ }^{21}$. Then, the participants were positioned in the prone position for the location and placement of the electrodes:

- ICL: $6 \mathrm{~cm}$ laterally to the space between the spinous process of $\mathrm{L} 2-\mathrm{L}^{21}$.

- LM: Positioned on the line connecting the posterior superior iliac spine and the space between L1-L2 at the level of L5 ${ }^{15}$.

The muscles were located, and the electrodes were positioned unilaterally and longitudinally oriented with the muscle fiber on the dominant $\operatorname{side}^{20}$. The area of placement of the electrodes was shaved, and the skin abrasion with gauze was performed to decrease the impedance, and the skin was cleaned with alcohol ${ }^{21}$. The electrodes used were the $\mathrm{Ag} / \mathrm{AgCl}$ surface electrodes, active, with pre-amplification with 20 times gain. They were positioned in a bipolar configuration, with a $1 \mathrm{~cm}$ diameter pickup area and distance of $2 \mathrm{~cm}$ between them. The reference electrode was positioned in the ulnar styloid process on the dominant side ${ }^{12}$. To capture the electromyographic signals, it was used a biological signal acquisition module, 8-channel EMG830c (EMG System $^{\circ}$ ), a EMGLab data collection, processing and storage software, calibrated with sampling frequency of $2000 \mathrm{~Hz}$, total gain of 2000 times (20 times on the sensor and 100 times on the equipment) and system impedance of $109 \Omega$, mutual rejection module $>100 \mathrm{~dB}$ and signal-to-noise ratio $<3 \mu \mathrm{V}$ RMS.

The maximum voluntary isometric contraction (MVIC) was subsequently collected for the standardization of the electromyographic signal. The RA muscle was assessed with the participants sitting on the stretcher, with knees flexed at $90^{\circ}$, feet on a support base and LL united ${ }^{11}$. The UL were positioned crossed in front of the chest, and the torso slightly inclined backwards ${ }^{11}$. The feet and trunk were stabilized by the evaluators, while the participants applied the maximum force to flex the torso anteriorly ${ }^{11,15}$.

The IO and EO muscles were assessed in lateral decubitus with the side to be assessed upwards ${ }^{11}$. The knees remained flexed at $90^{\circ}$, and the UL united and crossed in front of the torso, while the evaluators stabilized the knees, hip, shoulders, and elbows ${ }^{11}$. The participants applied force to the torso lateral flexion direction ${ }^{11,15}$. The ICL and LM muscles were assessed with the participants in the prone position, with the LL positioned on the box, from the ASIS region until the feet, and the torso outside the box ${ }^{11,19}$. The participants were stabilized in the regions of the ankles, knees, and hips with Velcro staps ${ }^{19}$. Another strap was positioned $n$ the region of the shoulder blades to limit the torso extension, and the participants were encouraged to apply the maximum force in the direction of the torso extension ${ }^{11,15}$.

All the MVIC evaluations were performed twice with muscle contraction sustained for four seconds and with one minute of rest ${ }^{4}$. Oral motivation was given at all times, as well as instructions at the beginning of the evaluations, on which muscle would be assessed to its better recruitment. The highest value was used for data analysis ${ }^{11}$.

The electromyographic analysis was done with the software Matlab during the MET. A $4^{\text {th }}$ order Butterworth high-pass filter with a cutoff frequency of $20 \mathrm{~Hz}$ and a 4th order Butterworth low-pass filter with a cutoff frequency of $500 \mathrm{~Hz}$ were used. The Root Mean Square (RMS) of the muscles were normalized by the highest value obtained on MVIC.

This study was approved by the Research Ethics Committee of the School of Philosophy and Sciences of UNESP/Marília (re- 
port number 1.054.270). All the participants were informed about the research and signed a Free and Informed Consent Term (FICT).

\section{Statistical analysis}

The statistical analysis was performed using PASW 18.0 (SPSS Inc., Chicago, USA). The parametric electromyographic data were presented as the mean and standard deviation, and the nonparametric as median, minimum and maximum. The Shapiro-Wilk test was used to check data normality. After checking, the multivariate analysis of variance (MANOVA) was used to compare the characteristics of the subjects. Age and body mass index (BMI) of the participants were used as covariates for parametric data analysis, using multivariate analysis of covariance (MANCOVA). The Kruskal-Wallis test was used for nonparametric data analysis. The significant value adopted was $\mathrm{p}<0.05$.

\section{RESULTS}

The average of the age of the CG was 6 years lesser when compared with the LBPG, apart from presenting lower BMI. Therefore, the age and BMI were considered as covariates in the statistical analysis of the electromyographic activity for the comparison of groups (Table 1).

Regarding the data analysis of the ICL and LM muscles electromyography, no significant differences were observed in MET in the comparison between the groups ( $\mathrm{p}=0.331$ and $\mathrm{F}=1.148$ ) (Table 2). The RA and EO muscles showed a significant difference, whereas the IO muscle showed no difference between the groups in MET, as can be seen in table 3 .

MST and MET values are shown in figure 3. Muscle strength showed no significant difference. A significant difference was observed in muscle endurance when comparing the groups. In the LBPG the difference was lower.

Table 1. Demographic and pain characteristics of the participants (Mean \pm SD)

\begin{tabular}{|c|c|c|c|c|}
\hline & LBPG $(n=20)$ & CG $(n=15)$ & $\begin{array}{c}\text { MANOVA } \\
\text { p-value }\end{array}$ & $\begin{array}{c}\text { MANOVA } \\
\text { F-value }\end{array}$ \\
\hline Age (years) & $45.90 \pm 8.45$ & $39.80 \pm 8.01$ & 0,038 & $4.661^{*}$ \\
\hline Body mass index $(\mathrm{kg} / \mathrm{m})$ & $28.42 \pm 5.52$ & $24.19 \pm 3.44$ & 0,014 & $6.799^{*}$ \\
\hline Duration of low back pain (years) & $8.55 \pm 8.86$ & - & - & - \\
\hline Daily pain (VAS) & $3.97 \pm 2.54$ & - & - & - \\
\hline Pain on evaluation (VAS) & $0.85 \pm 1.64$ & - & - & - \\
\hline Roland Morris disability questionnaire & $4.57 \pm 5.30$ & - & - & - \\
\hline
\end{tabular}

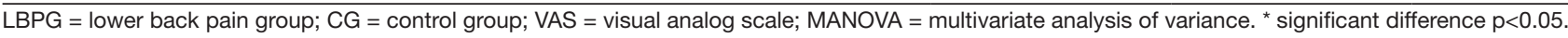

Table 2. Root Mean Square normalized data of the iliocostalis muscles and lumbar multifidus (mean \pm SD of parametric data)

\begin{tabular}{|c|c|c|c|c|}
\hline & $\begin{array}{c}\text { LBPG } \\
\text { Mean } \pm \text { SD }\end{array}$ & $\begin{array}{c}C G \\
\text { Mean } \pm \text { SD }\end{array}$ & p-value & F-value \\
\hline $\mathrm{ICL}$ & $0.77 \pm 0.15$ & $0.64 \pm 0.17$ & 0,175 & 1,928 \\
\hline LM & $0.83 \pm 0.16$ & $0.75 \pm 0.12$ & 0,618 & 0,253 \\
\hline
\end{tabular}

$\mathrm{ICL}=$ liliocostalis lumborum muscle; $\mathrm{LM}=$ lumbar multifidus muscle; LBPG = low back pain group; CG = control group.

Table 3. Root Mean Square normalized data of the internal and external oblique muscles, and rectus abdominis of the nonparametric data

\begin{tabular}{|c|c|c|c|c|c|c|c|}
\hline & \multicolumn{3}{|c|}{ LBPG } & \multicolumn{3}{|c|}{ CG } & \multirow[t]{2}{*}{ p-value } \\
\hline & Median & Minimum & Maximum & Median & Minimum & Maximum & \\
\hline 10 & 0.98 & 0.3 & 6.23 & 0.52 & 0.12 & 2.5 & 0.053 \\
\hline $\mathrm{EO}$ & 0.51 & 0.01 & 1.32 & 0.14 & 0.01 & 2.5 & $0.008^{*}$ \\
\hline $\mathrm{RA}$ & 0.31 & 0.1 & 2.99 & 0.2 & 0.08 & 4.05 & $0.009^{\star}$ \\
\hline
\end{tabular}

$\mathrm{IO}=$ internal oblique muscle; $\mathrm{EO}=$ external oblique muscle; $\mathrm{RA}=$ rectus abdominal muscle; $\mathrm{LBPG}=$ low back pain group; $\mathrm{CC}=\mathrm{control}$ group. ${ }^{*}$ significant difference $\mathrm{p}<0.05$.

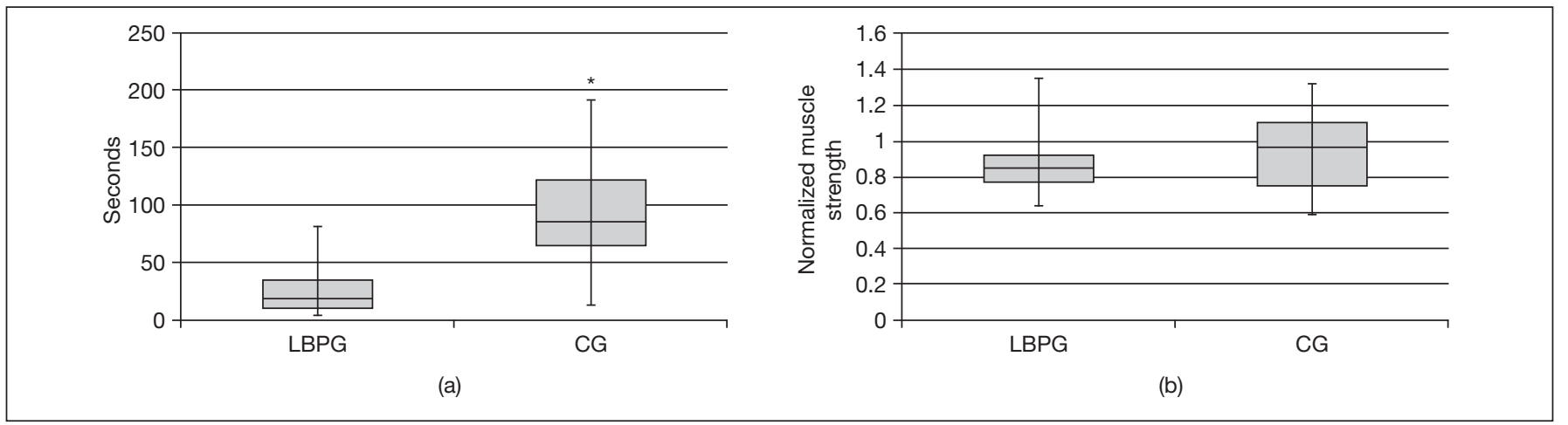

Figure 3. Box plot showing the median, interquartile and minimum and maximum intervals in muscle endurance and muscular strength tests for both groups

(a) MET = muscle endurance test $(p=0.001)$; (b) MST = muscle strength test $(p=0.172)$; LBPG = low back pain group; CG = control group; ${ }^{*}$ Significant difference $(p<0.05)$. 


\section{DISCUSSION}

There was no significant difference between groups $(\mathrm{p}=0.172)$ in MST. However, the CG had higher values on the torso extensors strength. It is known that pain reduces muscle activity ${ }^{6}$. The explanation for the non-appearance of significant difference in this study may be related to the fact that the LBPG had high values of daily pain associated with the presence of limitations showed by the RMDQ ${ }^{5}$, leading to the restriction of movement in the region with pain, as well as of the whole body. Therefore, pain improvement may explain the elevated values of muscle activation ${ }^{5,6}$. Avoiding movements that use the area of the lumbar spine favors sedentarism, and as a result, the overweight shown by the high BMI of the participants with $\mathrm{LBCP}^{2,22,23}$. The overweight and the presence of a greater amount of fat facilitate fat infiltration in the muscle area of the ICL and LM muscles, and that increase is indicative of muscle atrophy that leads to a reduction in the torso extensors strength ${ }^{22}$.

The MET results show a greater muscle endurance in the CG, with time values higher than the LBPG $(\mathrm{p}<0.001)$. Previous studies have shown that MET is related with pain and the prognosis of LBP development, and individuals who present less than 58 seconds are three times more likely to have LBP than those who maintained more than 104 seconds $s^{19,23,24}$. This difference in MET may be due to the predominance and prevalence of type II muscle fibers and reduction of type I muscle fibers of the ICL and LM muscles in the LBPG, which makes it difficult to maintain a horizontal posture during MET and in the postures during daily activities ${ }^{23,25}$.

The electromyography results give information regarding neuromuscular activity ${ }^{6}$, and surface electrodes are recommended, primarily because this is a volunteer activity, and therefore, it is preferable to use surface electrodes ${ }^{26}$. In addition, the use of needle electrodes in a sustained contraction could cause discomfort to participants. Due to the use of surface electrodes in the bipolar configuration, there is a high rejection rate of the common-mode, which purpose is to eliminate external noise, which results in a better quality of the electromyographic signal ${ }^{26}$. When analyzing the electromyography data with the MET data, it was observed that the CG showed less muscle recruitment of all evaluated muscles. Greater results in muscle activity in the LBPG may have a relationship with the number of traction units selected for the $\operatorname{task}^{5,26}$. Thus, lower values of muscle activation in the CG may be related to the greater number of motor units recruited at the time of the test, with a lower amplitude value of muscle recruitment ${ }^{4-6,26,27}$. The higher levels of muscle activation in the LBPG were evident in the EO and RA muscles, considered global stabilizers muscles ${ }^{10}$, which showed statistically significant results $(\mathrm{p}<0.05)$. The results of this study corroborate the studies that showed higher activation of the global muscles. However, this strategy that aims at increasing the torso stiffness by increasing the agonist and antagonist activation, make the global muscles act as local, and in situations of higher stability requirement it may have a harmful potential and increase pain ${ }^{7-9}$.

The CG showed better results in muscle endurance and recruitment in the tests conducted, and endurance is an aspect of performance and functional assessment. Women who were in the LBPG showed deficits in the neuromuscular capacity. The central nervous system uses this information to develop and correct movement patterns in our daily activities, i.e., pain produces a favorable environment for the onset and development of lesions and pain.

\section{CONCLUSION}

Women with chronic low back pain had lower muscle endurance and more muscle requirement of the global muscles when compared with women without pain. Thus, it is important to note that rehab training should also include muscle endurance training of the torso extensor and focus on the motor control with the purpose of reorganizing muscle recruitment with emphasis on the local system.

\section{REFERENCES}

1. Cho KH, Beom JW, Lee TS, Lim JH, Lee TH, Yuk JH. Trunk muscles strength as a risk factor for nonspecific low back pain: A pilot study. Ann Rehabil Med. 2014;38(2):234-40.

2. Conway R, Behennah J, Fisher J, Osborne N, Steele J. Associations between trunk extension endurance and isolated lumbar extension strength in both asymptomatic participants and those with chronic low back pain. Healthcare. 2016;4(3). pii: E70.

3. Ono R, Higashi T, Takahashi O, Tokuda Y, Shimbo T, Endo H, et al. Sex differences in the change in health-related quality of life associated with low back pain. Qual Life Res. 2012;21(10):1705-11.

4. Nelson-Wong E, Alex B, Csepe D, Lancaster D, Callaghan JP. Altered muscle recruitment during extension from trunk flexion in low back pain developers. Clin Biomech. 2012;27(10):994-8.

5. Butler HL, Hubley-Kozey CL, Kozey JW. Changes in electromyographic activity of trunk muscles within the sub-acute phase for individuals deemed recovered from a low back injury. J Electromyogr Kinesiol. 2013;23(2):369-77.

6. Schmit EF, Brito JD, Nóbrega SR, Araújo-Neto SA, Andrade PR, Ferreira JJ, et al Efeitos da fisioterapia na força, atividade mioelétrica e dor, em lombálgicos crônicos. ConScientiae Saúde. 2016;15(2):183-90.

7. Hodges PW, Moseley GL, Gabrielsson A, Gandevia SC. Experimental muscle pain changes feedforward postural responses of the trunk muscles. Exp Brain Res. 2003;151(2):262-71

8. D'hooge R, Hodges P, Tsao H, Hall L, Macdonald D, Danneels L. Altered trunk muscle coordination during rapid trunk flexion in people in remission of recurrent low back pain. J Electromyogr Kinesiol. 2013;23(1):173-81.

9. Tsao H, Galea MP, Hodges PW. Driving plasticity in the motor cortex in recurrent low back pain. Eur J Pain. 2010;14(8):832-9.

10. Bergmark A. Stability of the lumbar spine. A study in mechanical engineering. Acta Orthop Scand Suppl. 1989;230:1-54.

11. Vera-Garcia FJ, Moreside JM, McGill SM. MVC techniques to normalize trunk muscle EMG in healthy women. J Electromyogr Kinesiol. 2010;20(1):10-6.

12. Rossi DM, Morcelli MH, Marques NR, Hallal CZ, Gonçalves M, Laroche DP, et al Antagonist coactivation of trunk stabilizer muscles during Pilates exercises. J Bodyw Mov Ther. 2014;18(1):34-41.

13. Astfalck RG, O'Sullivan PB, Straker LM, Smith AJ, Burnett A, Caneiro JP, et al. Sitting postures and trunk muscle activity in adolescents with and without nonspecific chronic low back pain: an analysis based on subclassification. Spine. 2010;35(14):1387-95.

14. Morcelli MH, Faganello FR, Navega MT. Avaliaçáo da flexibilidade e dor de idosos fisicamente ativos e sedentários. Ter Man. 2010;8(38):298-304.

15. Schinkel-Ivy A, Nairn BC, Drake JD. Investigation of trunk muscle co-contraction and its association with low back pain development during prolonged sitting. J Electromyogr Kinesiol. 2013;23(4):778-86.

16. Nusbaum L, Natour J, Ferraz MB, Goldenberg J. Translation, adaptation and validation of the Roland-Morris questionnaire--Brazil Roland-Morris. Braz J Med Biol Res. 2001;34(2):203-10.

17. Cavazzotto TG, Tratis L, Ferreira SA, Fernandes RA, Queiroga MR. [Muscular static strength test performance: comparison between normotensive and hypertensive workers]. Rev Assoc Med Bras. 2012;58(5):574-9. English, Portuguese. 
18. Gruther W, Wick F, Paul B, Leitner C, Posch M, Matzner M, et al. Diagnostic accuracy and reliability of muscle strength and endurance measurements in patients with chronic low back pain. J Rehabil Med. 2009;41(8):613-9.

19. Alaranta H, Luoto S, Heliövaara M, Hurri H. Static back endurance and the risk of low-back pain. Clin Biomech. 1995;10(6):323-4.

20. Hoffman M, Schrader J, Applegate T, Koceja D. Unilateral postural control of the functionally dominant and nondominant extremities of healthy subjects. J Athl Train. 1998;33(4):319-22.

21. Marques NR, Hallal CZ, Gonçalves M. Padrăo de co-ativaçấo dos músculos do tronco durante exercícios com haste oscilatória. Motriz Rev Educ Fis. 2012;18(2):245-52.

22. Teichtahl AJ, Urquhart DM, Wang Y, Wluka AE, Wijethilake P, O'Sullivan R, et al. Fat infiltration of paraspinal muscles is associated with low back pain, disability, and structural abnormalities in community-based adults. Spine J. 2015;15(7):1593-601.

23. Davarian S, Maroufi N, Ebrahimi I, Farahmand F, Parnianpour M. Trunk muscles strength and endurance in chronic low back pain patients with and without clinical instability. J Back Musculoskelet Rehabil. 2012;25(2):123-9.

24. Mbada CE, Ayanniyi O, Ogunlade SO, Orimolade EA, Oladiran AB, Ogundele AO, et al. Rehabilitation of back extensor muscles' inhibition in patients with long-term mechanical low-back pain. ISRN Rehabil. 2013;1-11.

25. Mazis N, Papachristou DJ, Zouboulis P, Tyllianakis M, Scopa CD, Megas P. The effect of different physical activity levels on muscle fiber size and type distribution of lumbar multifidus. A biopsy study on low back pain patient groups and healthy control subjects. Eur J Phys Rehabil Med. 2009;45(4):459-67.

26. De Luca CJ. The use of surface electromyography in biomechanics. J Appl Biomech. 1997;13(2):135-63.

27. Sánchez-Zuriaga D, López-Pascual J, Garrido-Jaén D, García-Mas MA. A comparison of lumbopelvic motion patterns and erector spinae behavior between asymptomatic subjects and patients with recurrent low back pain during pain-free periods. J Manipulative Physiol Ther. 2015;38(2):130-7. 